\title{
Assessment of heat and cold wave events over West Africa using three regional climate models
}

\author{
Mojisola Oluwayemisi Adeniyi ${ }^{1, \star}$ and Samuel Oluwaseyi Oyekola ${ }^{2}$
}

${ }^{1}$ Department of Physics, University of Ibadan, Ibadan, Nigeria

${ }^{2}$ Department of Meteorology and Climate Science, Federal University of Technology, Akure, Nigeria

\author{
Article history \\ Received April 23, 2016; accepted January 10, 2017. \\ Subject classification: \\ Temperature regions, heat wave, cold wave, inter-tropical convergence zone, low pressure center.
}

\begin{abstract}
This paper computes heat (cold) waves for four homogeneous temperature regions over west Africa based on excess heat (cold) index and heat (cold) stress. Era Interim daily minimum and maximum temperature data, National Centers for Environmental Prediction-National Center for Atmospheric Research Reanalysis mean daily sea level pressure, $850 \mathrm{hPa}$ winds and $500 \mathrm{hPa}$ geopotential height are used as the surrogate observed data while simulated data are outputs of three Coordinated Regional Climate Downscaling Experiment models (CNRM-ARPEGE, SMHI-R$C A$ and UQAM-CRCM). Heat (cold) wave is calculated for 2001-2008 with respect to 1989-2000 reference period. Findings show that heat wave fluctuates with Inter-tropical Convergence Zone (ITCZ) from Guinea-Savannah (GS) region in February-March to the Western Sahel between June and August. Frequency of heat wave is fairly stable except in 2007 and 2008 when it increases. The amplitude of heat wave increases from 2001 to 2008, probably due to global warming. With respect to the reanalysis; CNRM-ARPEGE, SMHI-RCA and UQAM-CRCM all simulate comparable spatial and temporal variations in heat waves. However, SMHI generally overestimates the magnitude of heat waves. The models also simulate cold waves similar to Era Interim except at GS. Persistence of warm (cold) low (high) pressure center at the surface and warm (cold) high (low) pressure center at the mid troposphere over a particular area increases the frequency of heat (cold) wave. Variations in magnitude of pressure gradient control the amplitude of the waves. Southeasterly surface wind intensifies during heat waves events while northerly and northeasterly surface winds prevail during cold wave events.
\end{abstract}

\section{Introduction}

There has been more temperature increase in the northern hemisphere than southern hemispheres over the last century since the 1950s [Rebetez and Reinhard, 2008]. Positive and negative temperature extremes usually have negative impacts on hydrological processes, society, economy, ecosystems, and on human health [Parmesan et al., 2000]. West Africa as a tropical region experiences hot weather and climate throughout the year. The weather and climate are affected by the fluctuations of both Inter-tropical Convergence Zone (ITCZ) and Sahara Thermal Low (STL) [Adeniyi, 2014a]. The fluctuations result in, intra-annual variations of temperature with a peak in the summer between July and August at the Sahel. Lavaysse et al. [2009] observed that the ITCZ and STL remain quasi-stationary during the months of July and August at their northernmost limit of around $22^{\circ} \mathrm{N}$. This may lead to uncomfortable heat stress especially in years when the peak is higher than the climatology period. The weather and climate variabilities experienced in the recent times have aroused the interest of researchers in investigation of trends in temperature variability and extremes in the tropics. However the studies only cover a limited part of West Africa. New et al. [2006], for instance, included four Nigerian stations in a regional extreme temperature study. Eludoyin et al. [2014] also analyzed trends in temperature variables in Nigeria. In addition, Oguntunde et al. [2012] analyzed trends in temperature time series over Nigeria for the period 1901 - 2000. They found warming during the period 1930 - 1941 and 1981 - 2000, but cooling in the period 1901 - 1929 and 1942 - 1980. Furthermore, [Abatan et al., 2015] found significant increase in the frequency of hot extreme and reduction in frequency of cold extreme events, higher annual trend in warm night during June-August (JJA) and September-November (SON) than other seasons at the Guinea coast and Sahel in Nigeria. A study on changes in indices of daily temperature and precipitation extremes in Northwestern Nigeria also reported significant increase in temperature indices that are related to temperature increase [Abdussalam, 2015]. Gbode et al. [2015] studied the changes in extreme temperature and 
precipitation indices in Kaduna (Northern Nigeria). They found warming trends, increase in number of cool nights, more warm days; strong increase in the number of warm spells, slight increase in annual total rainfall and changes in the maximum number of extremely wet days. In West Africa, Mouhamed et al. [2013] investigated the trends in extreme temperature and precipitation over the Sahel from 1960-2010. They found negative trend in frequency of cool nights, increase in frequency of warm days and spells, reduction in annual total rainfall and maximum number of consecutive wet days. All these findings suggest that further studies should be carried out on heat and cold waves variations over West Africa. Regional climate models should also be used to carry out this study to determine the applicability of such models to the future projection of heat and cold waves over West Africa because of the possible disastrous impacts of such in any locality [Guirguis et al., 2014; Parmesan et al., 2000].

Heat wave is an extended period of excessively hot and sometimes also humid weather relative to normal climate patterns for the seasons in a certain region. It causes temporary modifications in lifestyle and may have adverse health effects on the affected population depending on the intensity [Robinson, 2001]. Heat kills by pushing the human body beyond its limits. In extreme heat and high humidity, evaporation is slowed and the body must work extra hard to maintain a normal temperature. On the other hand, a cold wave can be defined as a sudden invasion of very cold air over a large area leading to unusually large and rapid reduction in temperature. It can also be a prolonged period of excessively cold weather. A cold wave can damage plants due to inadequate energy for photosynthesis and affect agricultural production negatively. It is also dangerous to human health.

There is dearth of observed daily station temperature data that cover West Africa, the few available stations are country based. However, monthly gridded observed temperature data are available, for example monthly temperature Time Series (TS) produced by Climate Research Unit (CRU) of the University of East Anglia and Willmott and Matsuura University of Delaware (UDEL) are available. This constraint has pushed daily temperature analysis over West Africa to the use of surrogate observed (reanalysis) data. Therefore, this study uses daily maximum and minimum temperature from reanalysis data. For reliable analysis of heat and cold waves over West Africa, bearing in mind that there are varied temperature sub-regions in the region; homogeneous temperature regions are necessary for the area averaging needed in the computation of excess heat and cold. There has been no study that delineates West Africa into homogeneous temperature regions, studies have been based on latitudinal or ecological zones [Nicholson et al., 2000; Abiodun et al., 2013; Abatan et al., 2015]. Abatan et al. [2015] revealed that stations in the same latitudinal zones may not have similar temperature trend. Such zones are not homogeneous temperature zones. This necessitates the homogeneous regionalization of temperature based on the similarities in their variances. Also, there has been no study on heat and cold waves occurrence over West Africa despite the increased warming that is well documented. Most temperature studies have been on trends. The timing, frequency and amplitude of heat and cold waves over the different temperature regions of West Africa remain undocumented. If the present or historical state of heat and cold waves are known at the different temperature regions of West Africa, the future state should also be projected using General circulation models and downscaled using skillful regional climate models. This calls for evaluation of available regional climate models for possible application in climate downscaling. The downscaled projected heat and cold waves could serve as working paper for proper adaptation and mitigation plans against the disastrous consequences of such events.

Heat and cold stresses have been calculated using various indices. To start with, Watts and Kalkstein [2004] developed the Heat Stress Index. Furthermore, Adeniyi [2009] used Temperature humidity index and Wind chill index over Ibadan. The indices proposed by the Expert Team on Climate Change Detection and Indices (ETCCDI), have also been used [Frich et al., 2002; Peterson, 2002; Donat et al., 2013]. Moreover, Kalkstein and Valimont [1986] used Weather Stress Index.

A number of indices have also been used to define and calculate warm or cold spells (heat or cold wave). The index with a number of time steps in daily maximum or minimum temperature above a particular threshold value has been widely used [Kunkel et al., 1999; Meehl and Tebaldi, 2004; Alexander et al., 2006]. Combination of threshold exceedances of both daytime high or nighttime low temperatures [Easterling et al., 1997] has also been used. The latter defines heat wave event as at least three days with a maximum temperature above the 80th percentile (based on reference peiod) for that day followed by a minimum temperature above the 80th percentile for that day. This was done to include periods with warm daily maximum temperatures that do not cool off much at night. Occurrence of consecutive nights with high temperature following consecutive warm days negatively affect human health, as well as ecosystems [Changnon et al., 1996; Easterling et al., 1997]. Nairn and Fawcett [2013] defined heat wave in a similar manner but used mean temperature which is the average of the minimum and maximum 
daily temperature. They calculated excess heat index as the extraordinary intense heat which emanates from a high afternoon temperature that is not sufficiently cooled during the night due to extremely high night temperature. Instead of 80th percentile threshold they used 95 th and 5 th percentiles respectively, for heat and cold wave thresholds. The variabilities in magnitude and frequency of heat and cold waves can be understood by studying the dynamics of heat and cold waves. This will probably expose part of the causes and mechanisms of the variabilities, since such has not been documented over this region.

This paper aims at studying the variability of heat and cold waves in homogeneous temperature region over West Africa. The required homogeneous regions for the heat and cold wave analysis are not yet documented, as a means to an end, this paper therefore delineates West Africa into homogeneous daily temperature regions using surrogate observed (reanalysis) data. It then computes heat and cold waves over the temperature regions and investigates their dynamics. It finally assesses the performance of three regional climate models in simulating the surrogate observed heat and cold waves.

\section{Data}

The European Center for Medium-Range Weather Forecasts (ECMWF) Era-Interim (ERAINT) reanalysis daily minimum and maximum temperature data are used as the surrogate observed data while the simulated daily temperatures are the output of three Coordinated Regional Climate Downscaling Experiment (CORDEX) models; CNRM-ARPEGE, SMHI-RCA and UQAM-CRCM. The three models are the only ones with available minimum and maximum daily temperature data for this study. The three CORDEX models are listed in Table 1. Details of the CORDEX simulations; the initial boundary conditions, sea surface temperature, physical parameterizations and projections used in the different models can be found in Nikulin et al. [2012]. All the daily data cover the period of 1989-2008. Mean daily zonal and meridional wind $(850 \mathrm{hPa})$, sea level pressure and $500 \mathrm{hPa}$ geopotential height fields from National Centers for Environmental Prediction/National Center for Atmospheric Research (NCEP-NCAR) Reanalysis are also used. CRU TS 3.22 [Harris et al., 2014] observed monthly temperature from 1948 to 2012 was used to study the connection between temperature variation and oscillations of tropical oceans. The tropical oceanic indices used are: Pacific Decadal Oscillation (PDO, Zhang et al., 1997; Mantual et al., 1997], Atlantic Multidecadal Oscillation (AMO, Enfield et al. 2001], Tropical Northern Atlantic [TNA, Enfield et al. 1999] and Dipole Mode Index [DMI, Saji et al., 1999]. DMI is from 1958-2010 while PDO, TNA and AMO are from 1948-2012.
The TNA [Enfield et al., 1999] is the anomaly of the monthly Sea Surface Temperature (SSTA) averaged over $5.5 \mathrm{~N}$ to $23.5 \mathrm{~N}$ and $15 \mathrm{~W}$ to $57.5 \mathrm{~W}$. Details of TNA computation are in Enfield et al. 1997. The AMO which is also based on the Atlantic Ocean is the decadal running mean of the SSTA at the northern hemisphere [Enfield et al., 2001]. The PDO is the first principal component of the anomalies of the monthly SST in the North Pacific Ocean [Zhang et al., 1997; Mantua et al., 1997]. The DMI [Saji et al., 1999] is a measure of the east-west temperature gradient over the tropical Indian Ocean; it is connected to the Indian Ocean Dipole. It is computed as the difference between the Western Tropical Indian Ocean SST anomaly and southeastern tropical Indian Ocean SSTA indices. The former is an index of the surface temperature at the Western tropical Indian Ocean which is the SST anomaly within $50^{\circ} \mathrm{E}-70^{\circ} \mathrm{E}, 10^{\circ} \mathrm{S}-10^{\circ} \mathrm{N}$, while the latter is the SSTA over southeastern tropical Indian Ocean $\left(90^{\circ} \mathrm{E}-110^{\circ} \mathrm{E}, 10^{\circ} \mathrm{S}-0^{\circ}\right)$ Saji et al. [ 1999].

\begin{tabular}{lcc}
\hline Model & Institute & Short Name \\
\hline CNRM-ARPEGUE & $\begin{array}{c}\text { Centre National de Rechers } \\
\text { Meteorolo-Giques }\end{array}$ & CNRM \\
SMHI-RCA & $\begin{array}{c}\text { Sveriges Meteorologiska } \\
\text { och Hydrorology Inistitut } \\
\text { UQAM-CRCM }\end{array}$ & SMHI \\
& $\begin{array}{c}\text { Universite du Québec } \\
\text { á Motréal }\end{array}$ & UQAM \\
\hline
\end{tabular}

Table 1. Regional Climate Models employed in the study of heat and cold waves events. The models are on $50 \mathrm{~km}$ x $50 \mathrm{~km}$ grid (Source: Nikulin et al, 2012). Details of the initial and boundary conditions, sea surface temperature and physical parameterizations and projections used in the simulations are documented in Nikulin et al. (2012).

\section{Methodology}

\subsection{Regionalization of daily temperature}

Daily maximum temperature (Era Interim reanalysis) data over West Africa from 1989 to 2000 is delineated into homogeneous daily temperature regions with similar variations using S-mode Principal Component Analysis (PCA) and cluster analysis based on hierarchical methods. A delineation study over the East Asia monsoon region compared k-means and hierarchical methods of clustering [Awan et al., 2015]. The study shows that both methods have good performance in identifying homogeneous precipitation regions. The climatological Era Interim temperature data are subjected to Bartlett's test of Sphericity (BTS) to determine whether there are relationships or common variance among the variables in the dataset. Kaiser-Mayer-Olkin (KMO) is also conducted to ascertain the presence of distinct subgroups in the data set for the PCA to identify. Details of KMO, Bartlett's test of sphericity, PCA and cluster analyses can 
be found in Adeniyi [2014b]. All the days in the reference period in Era Interim daily maximum temperature data from 1989-2000 are included in the PCA. The PCA is conducted on the 4383 days starting from 1st of January 1989 to $31^{\text {st }}$ December 2000 over 2310 grids .The PCA is conducted on correlation matrix. Significant PCs with eigenvalue greater than one are retained based on the eigenvalue one rule of Kaiser [1960] and scree criteria of Cattell [1966]. The retained PCs are used for the cluster analysis to group the retained PCs and also to reduce the dimension [Gong and Richman 1995]. Area averages of mean daily temperature from the different homogeneous temperature regions are then calculated and used for heat and cold wave analyses.

Hierarchical methods (three) are tested and the best method is employed for the clustering analysis using squared Euclidean distance as the similarity measure. The tested hierarchical methods are: nearest neighbour, centroid and Ward. The nearest neighbour method allows a new member to be assigned to the cluster which consists of most common members to the incoming one based on the similarity measure of distance. The nearest cluster takes the incoming member. The centroid method is a type of $\mathrm{k}$-means clustering which uses a single mean (central) vector to represent a cluster, centroid method requires the number of clusters to be fixed in advance, if the number of clusters is fixed to $\mathrm{N}$, then there will be $\mathrm{N}$ central vectors (clusters) and finding the members of the clusters becomes an optimization problem in which the best set of members for each clusters should be found. This problem is difficult to solve and it is termed NP hard that is the solution is non-deterministic polynomial time-hard [Leeuwen,1998]. Approximate solutions are then found. The centroid method finds a single center for each of the $\mathrm{n}$ clusters and assigns members to the nearest cluster center, such that the squared Euclidean distances from the cluster are minimized. There are two major disadvantages of this method, first, fixing the number of clusters ahead will lead to forced grouping not necessarily what the cluster members should be. Second, almost equal number of members is allowed in each cluster. This can lead to erroneous clustering, in which some members that should be in other clusters are forced into a cluster where they do not belong.

Ward's method considers the sum of squares within the resulting clusters [Ward 1963]. The Clarks and Hosking [1986] rule (equation 1) is considered to determine the number of clusters to specify [Adeniyi, 2014b]. In addition to the Clarks and Hosking rule, the number of natural breaks in the resulting clusters from the best method is also considered.

$$
N_{C}=1+\left(3.3 \log _{10} n\right)
$$

[Clarks and Hosking, 1986] where $\mathrm{N}_{\mathrm{c}}=$ maximum number of clusters and $n$ is the number of items (stations) to be clustered.

The PCA is conducted on grid values, so the approximate total coverage area $(\mathrm{km})$ is divided into virtual stations of $300 \times 300 \mathrm{~km}^{2}$, assuming maximum spacing to obtain the number of stations that can be located over West Africa, since the value is needed to calculate the allowed number of clusters.

The time series of the significant PCs and the clusters are tested for robustness by repeating the PCA and cluster analysis for two halve periods within the reference period. The period 1989-2000 is divided into 19891994 (6 years) and 1995-2000 (6 years) periods. There are 2191 data points in the period 1989-1994 while there are 2192 data points in the second period. The minimum 2191 days in each of the two periods is more than enough for a good PCA, based on Comrey and Lee [1992] and Tabachnick and Fidell [2001] who argued that PCA requires large data size because it depends on the correlation between the variables, and correlation requires large data size (length). They stated that a length of 300 is enough for determination of correlation between variables and consequently for PCA. They further stated that length of 1000 is perfect. Moreover, twelve years daily data (1989-2000) amounts to 4383 data points which is more than enough to show the daily variability in a data set. The annual variability is not as strong as the daily variability in temperature data, since the former is just a mean value over about 365 data points and the heat and cold wave analyses make use of daily data. The resulting time series from 1989-1994 and 1995-2000 period are subjected to paired students t-test at 0.05 level while the cluster patterns from the three different periods1989-1994; 1995-2000 and 1989-2000 are subjected to ANalysis Of VAriance (ANOVA) also at 0.05 level.

\subsection{Statistical Tests}

The PC time series and cluster patterns are checked for applicability of student $t$ test and ANOVA respectively. There are four major criteria that any data must satisfy before dependent student $t$-test can be conducted on it. The criteria are: (1) dependent variable must be continuous. (2) Dependent variable should consist of two corresponding categories. (3) If there are outliers in the observation they must not be 
significant. (4) The time series should satisfy normality assumption. The normality of data sets is determined by skewness, variables with skewness values that range between -1 and +1 are taken to be approximately normally distributed. For any dependent variable to be subjected to ANOVA, apart from the continuity, outlier and normality criteria, it should also satisfy the following:

(5) The observations in each category should be independent

(6) The independent variable should consist of at least two categorical, independent groups.

(7) The variances from the different categories should be homogeneous. The equality of variance test requirement for ANOVA is done by comparing the standard deviations in the three cluster patterns using the rule of thumb:' largest standard deviation must not be greater than twice the value of the smallest standard deviation'.

The dependent $\mathrm{t}$ statistic is calculated as

$$
t=\frac{\bar{x}_{\text {diff }}}{\sigma\left(x_{\text {diff }}\right) / \sqrt{N}}
$$

where $\chi_{\text {diff }}$ is the difference between the two corresponding categories

$\bar{\chi}_{\text {diff }}$ is the mean of $\chi_{\text {diff }}$

$\sigma\left(\chi_{\text {diff }}\right)$ is the standard deviation of $\chi_{\text {diff }}$ given by

$$
\sigma\left(\chi_{\text {diff }}\right)=\sqrt{\frac{1}{N}} \sum_{i+1}^{N}\left(\chi_{\text {diff }}-\bar{\chi}_{\text {diff }}\right)
$$

and $\mathrm{N}$ is the number of samples in the variable.

Dependent $\mathrm{t}$ - test is conducted with alpha $=0.05$ and the critical value of $t=1.960$ for 2 tailed test.

The null hypothesis for the $t$ - test is: there is no significant difference between the two PC time series (1989 - 1994 and 1995 - 2000) while the alternative hypothesis is: there is significant difference between the two PC time series.

If the calculated $t$ is greater than the critical $t$ (1.960), then the null hypothesis is rejected. This means that there is significant difference between the two PC time series and $\mathrm{p}<0.05$ and vice versa.

The ANOVA statistic is calculated using the same number of samples in each independent category since the cluster patterns from the three different periods cover the same area. The total number of sample in each period is 2310 since there are 2310 grids.

The mean and standard deviation are calculated for each independent category. The grand mean is also calculated as the mean of all the mean of individual ca- tegories. The grand total number of all the samples is calculated as sum of all the samples in the three different periods. The number of samples in individual independent category is $n=2310$. The grand total is $N$ which is $\mathrm{n} \times 3$ in this case $=6930$

The sum of the squared deviations about the mean (SS) is divided by the degrees of freedom to obtain the variance. The statistic is then calculated on the mean of the individual categories $(\mathrm{x})$ and the grand mean $\bar{x}$

$\mathrm{C}_{\mathrm{n}}=$ number of categories

$$
\begin{gathered}
S S_{B}=\sum_{i=1}^{C_{n}} n(x-\bar{x})^{2} \\
M S_{B}=S S_{B} / C_{n}-1 \\
S S E=\sum_{i=1}^{C_{n}}(n-1) s^{2} \\
M S_{E}=S S_{E} / N-C_{n} \\
F=M S_{B} / M S_{E}
\end{gathered}
$$

where,

$\mathrm{SS}_{\mathrm{B}}=$ Sum of squares of deviation from mean between the categories

$\mathrm{N}=$ Total number of samples in all the categories

$\mathrm{n}=$ Total number of samples in a category

$\mathrm{SS}_{\mathrm{E}}=$ Sum of squares due to standard deviation in each category

$S=$ Standard deviation of the samples

$\mathrm{F}=$ Anova coefficient

$\mathrm{MS}_{\mathrm{B}}=$ Mean sum of squares of deviation from mean between categories

$\mathrm{MS}_{\mathrm{E}}=$ Mean sum of squares due to error

The critical value of $\mathrm{F}$ at 0.05 level and the 2 by 6927 degrees of freedom is 2.9957. If the calculated $\mathrm{F}$ is greater than the 2.9957 then there is significant difference between the patterns of clusters obtained from the three different periods and $\mathrm{p}<0.05$ and vice versa.

\subsection{Extreme temperature indices}

The methodology of extreme temperature indices of Nairn and Fawcett [2013] is used in this study. Excess heat factor (EHF) which is the heat wave is the product of the significant excess heat index (EHIsig) and heat stress (EHIaccl).

The excess cold factor (ECF) on the other hand is the product of excess cold index (ECIsig) and cold stress (ECIaccl). It is referred to as the cold wave. These indices are used to study the spatial and temporal variability in daily temperature changes over West 
Africa. Daily Mean Temperature (DMT) is defined as;

$$
\mathrm{T}=\left(\mathrm{T}_{\max }+\mathrm{T}_{\text {min }}\right) / 2
$$

where $\mathrm{T}_{\max }$ and $\mathrm{T}_{\text {min }}$ are the maximum and minimum temperatures, respectively over a period of 24 hours. Warming is accompanied by variability in DMT [Moberg et al., 2000] since mean daily temperature includes the signatures of the day time and night time temperatures.

The EHIsig is given by:

$$
\text { EHIsig }=\left(\mathrm{T}_{\mathrm{i}}+\mathrm{T}_{\mathrm{i}+1}+\mathrm{T}_{\mathrm{i}+2}\right) / 3-\mathrm{T}_{95}
$$

where, EHIsig $\left({ }^{\circ} \mathrm{C}\right)$ measures the degree of excess heat and $\mathrm{T}_{95}$ is the $95^{\text {th }}$ percentile of the averaged daily temperature for the reference period $(1989$ - 2000) in a particular temperature region. The reference period of 1989-2000 is used based on the available CORDEX output data length, with the exclusion of the 20012008 period used for the heat and cold waves computation. This is done in order to isolate the excess heat and cold. Moreover, the anomaly in 1989-2000 temperature is significantly greater than the previous 30 years [NASA, 2008]. Positive EHIsig signifies that the three-day period of DMT is warmer than the $95^{\text {th }}$ percentile for the climatological period. $T_{i}$ is the DMT spanning a period of 2001-2008 on day $i$ in Kelvin.

$\mathrm{EHI}_{\text {accl }}$ is calculated by comparing the DMT averaged over three-day period and the previous 30 days. This is expressed as a short-term (acclimatisation) temperature anomaly given by:

$$
\mathrm{EHI}_{\mathrm{accl}}=\left(\mathrm{T}_{\mathrm{i}}+\mathrm{T}_{\mathrm{i}+1}+\mathrm{T}_{\mathrm{i}+2}\right) / 3-\left(\mathrm{T}_{\mathrm{i}-1}+\ldots+\mathrm{T}_{\mathrm{i}-30}\right) / 30
$$

where $T_{i}$ is the DMT on day $i$. Positive EHIaccl shows that the three-day DMT is hot compared to the previous 30 days. The three-day DMT comprises of the current and the following two days succeeding the previous 30 days. The unit is in Kelvin.

$$
\begin{aligned}
& \mathrm{EHF} \text { is given by: } \\
& \mathrm{EHF}=\operatorname{Max}(0, \text { EHIsig }) \times \max (1, \text { EHIaccl })
\end{aligned}
$$

All negative EHIsig values are set to zero, also all EHIaccl values that are less than 1 are set to 1 . Positive value of EHF indicates the existence of heat wave.

\subsection{Severe heat wave threshold}

As earlier stated heat wave occurs when the EHF is positive. For further analysis, severe EHF threshold is determined for each temperature region. In a heat wave impact study, Guirguis et al. [2014] observed regional variations in temperature threshold at which an impact is seen. This means that applicable threshold in different regions differ, so threshold values for severe heat wave are calculated on the basis of the temperature regions. The threshold value was calculated by plotting the cumulative distribution function $(\mathrm{CDF})$ using generalised Pareto distribution against the normalized EHF (normalizing the EHF values against the maximum observed EHF). The CDF is given by: [Juran 1974; Paul et al., 1997]

$$
\operatorname{Pr}(X>x)=1-\left(1-\frac{k x}{b}\right)^{\frac{1}{k}}
$$

where,

$$
k=\frac{\mu}{2 \sigma^{2}}-1 / 2
$$

and

$$
b=\mu(k+1)
$$

$\mu$ is the mean of the positive EHF values and $\sigma$ is the standard deviation in the positive EHF values

3.5 Influence of tropical oceans on temperature over West Africa

In order to gain more insight into the possible factors influencing the temporal and spatial variations in frequency and amplitude of heat and cold waves, the links between temperature and tropical oceanic indices (PDO, AMO, TNA and DMI) are investigated using Pearson correlation coefficient. Significant correlation at 0.05 level indicates possible causal effect on temperature variations over the years and temperature regions. Due to the spatial distance between the Indian Ocean and West Africa and also between the Pacific Ocean and West Africa, the DMI index lagged by a month temperature and PDO index lagged by two months temperature are used in the correlation analysis. The AMO and TNA with similar months of temperature are used.

\section{Results}

\subsection{PCA and Clusters}

The KMO and BTS reveal the suitability of a PCA analysis in the daily maximum temperature data over West Africa. The KMO value obtained is 0.995 which is a superb value for PCA showing that there exist distinct groups in the data set which can be identified by 

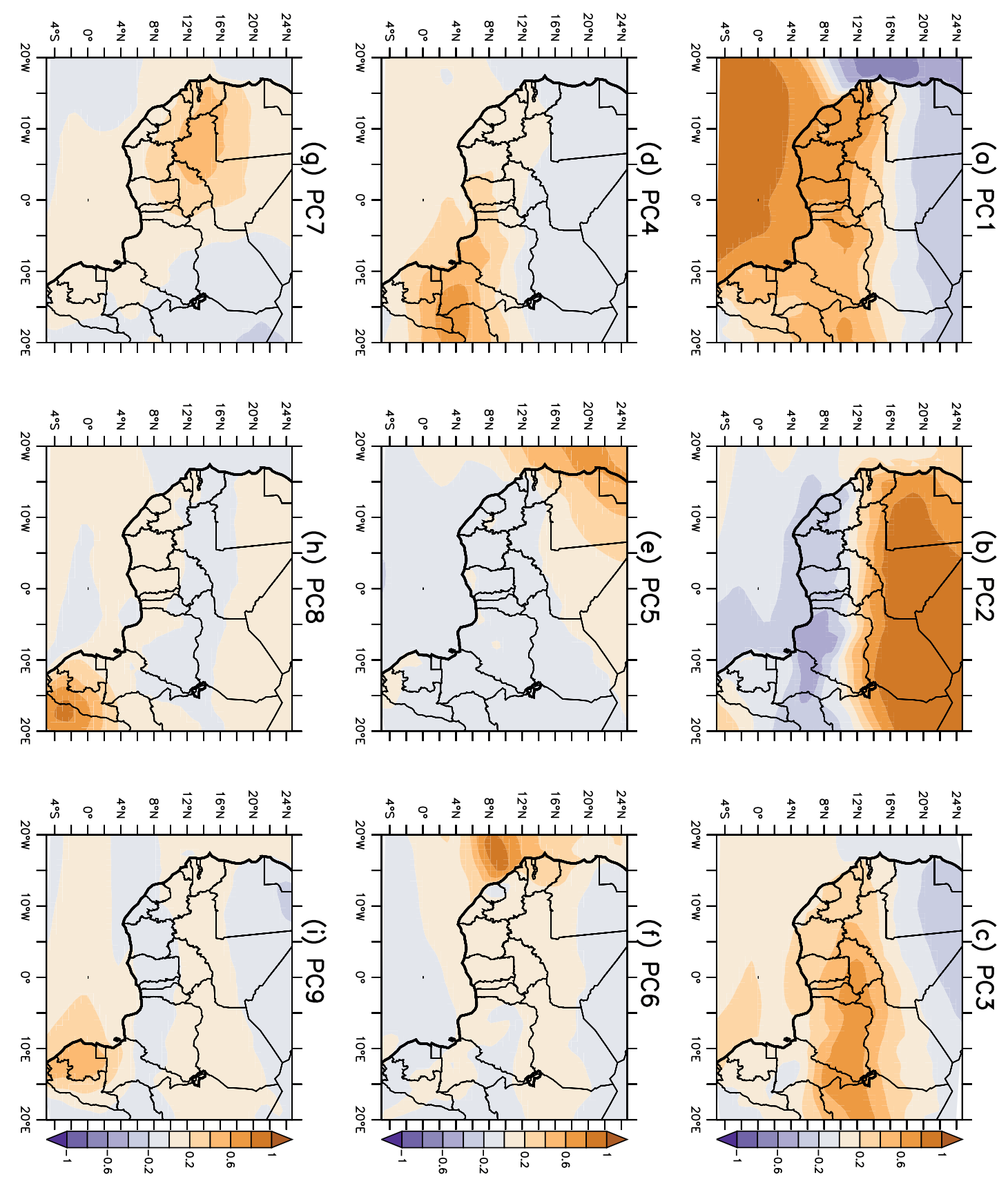

Figure 1. Nine significant principal components of daily maximum temperature over West Africa.

PCA. The significance of the BTS test is also high (p $<0.001$ ), this shows that there are common variances among the grids for the PCA to identify. The PCA conducted on the 4383 days starting from 1st of January 1989 to $31^{\text {st }}$ December 2000 over 2310 grids yield nine significant PCs based on the Cartell [1960] Scree criteria and eigenvalue one rule, Kaiser [1960]. The retained nine PCs explain 83.1 percentage of variance in the daily maximum temperature data. The percentage of explained variance in the temperature data from the two PCs conducted on the two six-year periods are almost the same with that from the 12-year period. For the $1989-1994$ period, $83.1 \%$ of variance is explained by the nine retained PCs, while $83.4 \%$ is explained by the nine PCs retained in the 1995-2000 period.

The PC time series from 1989-1994 periods and the cluster patterns from the three periods are all approximately normally distributed because the skewness values range from -0.47 to 0.24 . In addition, the equality of variance requirement for ANOVA done by comparing the standard deviations in the three cluster patterns, shows that the three cluster patterns have equal variances. Their standard deviations range from 2.43 to 2.61. Practically, the datasets meet all the requirements for both the $t$ test and ANOVA. The $t$-test conducted on the paired time series of the nine PCs retained from the two six-year periods shows that the time series are not affected by difference in the period. 
There is no significant difference between the time series at 0.05 level since, the obtained t values (range from -0.057 to 0.036 ) are less than the critical two tailed $t$ of 1.960 at, $p>0.05$. Furthermore, the ANOVA test conducted on the cluster patterns obtained from the three different periods reveals no significant difference between the cluster patterns. The obtained F, 2.891 is less than the critical F value (2.9957) based on $2 \times 6927$ degrees of freedom at 0.05 level and $p>0.05$. The conducted PCA and cluster analysis are therefore robust.

The rotated PC1 which is the most important mode of variability in the daily maximum temperature data explains $31.3 \%$ of variance in the temperature variability over West Africa.

High positive PC1 loadings $(>0.8)$ are located at the south Atlantic ocean and south western part of West Africa (Guinea-Savannah) while the highly negative component loadings $(<-0.8)$ are located at the northern Atlantic ocean (Figure 1).

The rotated PC2 explains $27.9 \%$ of the variance in the maximum temperature data. The PC2 describes a mode of temperature variation in which the Sahel has the highest maximum temperature which decreases towards the south. PC3 explains $8.0 \%$ of variance in the temperature data and the highest temperature is located at the lower Sahel and Savannah. PC4 explains $3.8 \%$ and PC 5 explains 3.3\% while each of the remaining PCs explains less than $3 \%$ of variance. PCs one to three appear to be the major contributors in the temperature variations over the land, (Figure 1).

Locations with high PC loadings are expected to be hotter on days with high positive PC score and colder on days with highly negative PC score. The contribution of each PC mode to each temperature region is assessed by the arithmetic mean temperature on days with highest positive score in each region. The area averaged temperatures from the different PCs are ranked to determine the most important modes of variation in each region. The mode of variation represented by PC2 is important in three of the four regions on land over West Africa. The area averaged temperature over the Western Sahel is highest (312.3 $\mathrm{K})$ on the day with the highest positive PC2 score (22May-1994). The area averaged temperature is also highest $(313.3 \mathrm{~K})$ over the Eastern Sahel on the day with highest positive PC2 score (22-May-1994). The day with highest positive PC2 score (22-May-1994) also has the highest area averaged temperature $(311.3 \mathrm{~K})$

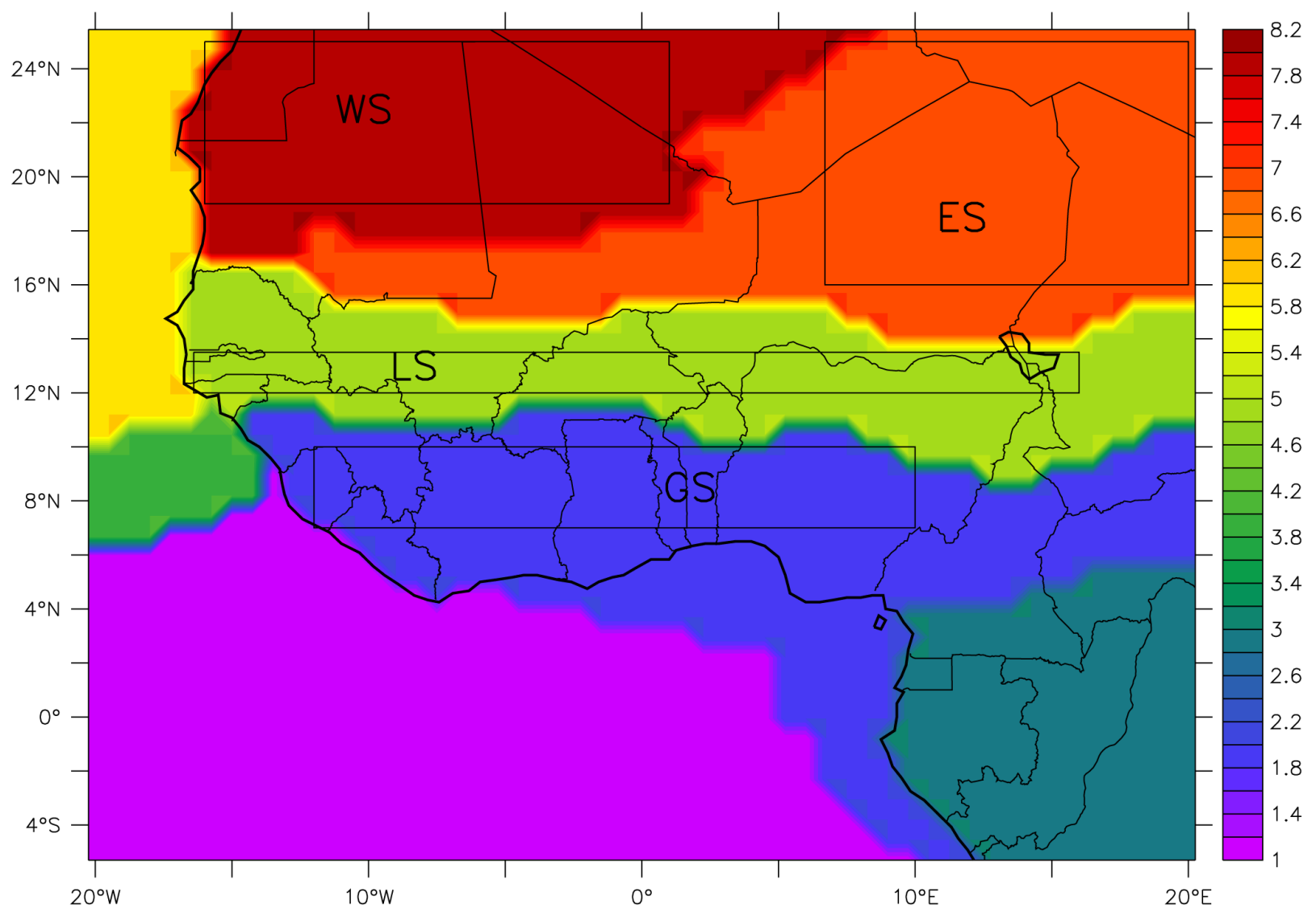

Figure 2. Homogeneous daily temperature regions of West Africa, it is based on nine principal components that explain $83.1 \%$ of variance in the reanalysis daily maximum temperature from 1989 to 2000 . WS is the Western Sahel, ES is the Eastern Sahel, LS is the Lower Sahel and GS is the Guinea-Savannah. 
(a) ERAINT WS

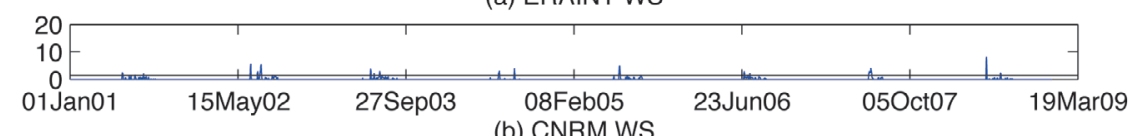

(b) CNRM WS

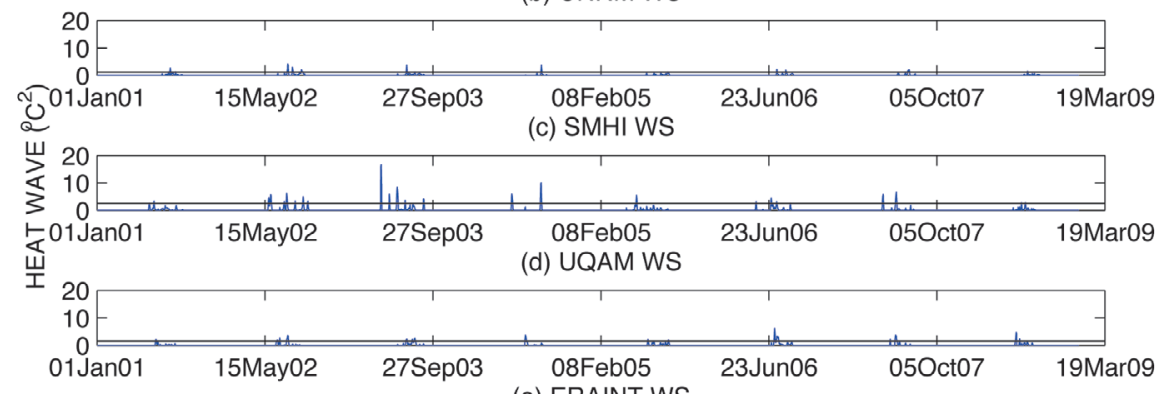

(e) ERAINT WS
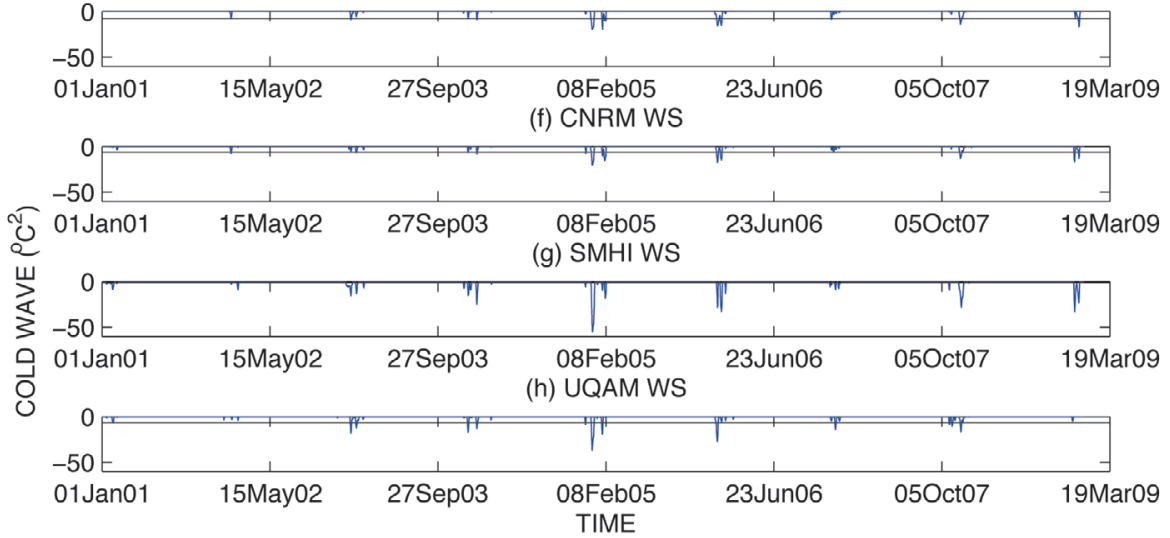

Figure 3. Daily surrogate observed and simulated heat and cold waves over Western Sahel (WS) in West Africa between 2001 and 2008.

(a) ERAINT ES

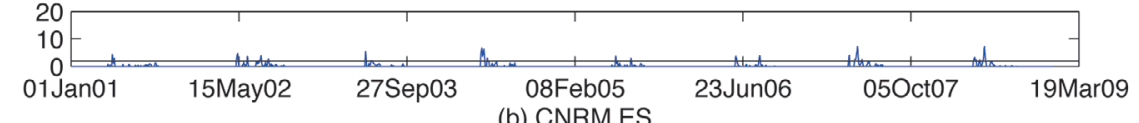

(b) CNRM ES

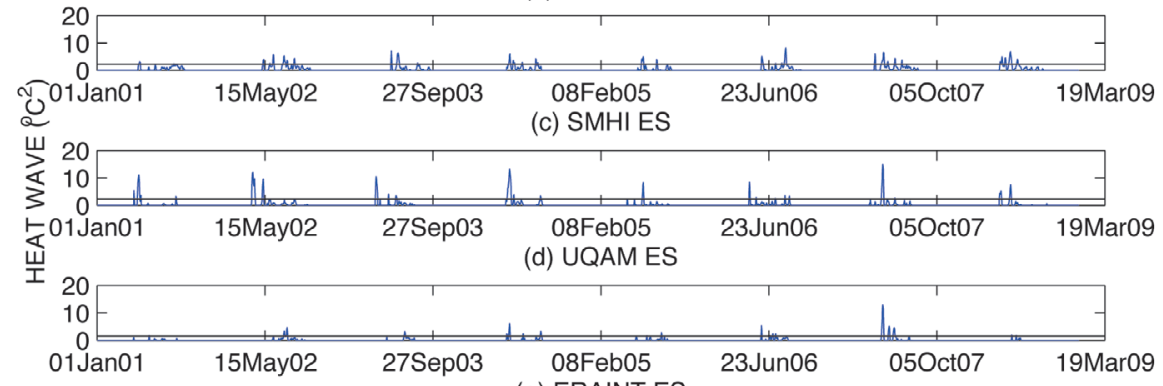

(e) ERAINT ES

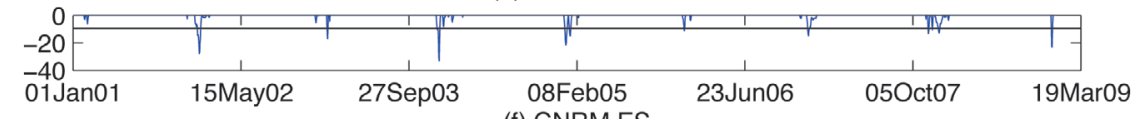

(f) CNRM ES

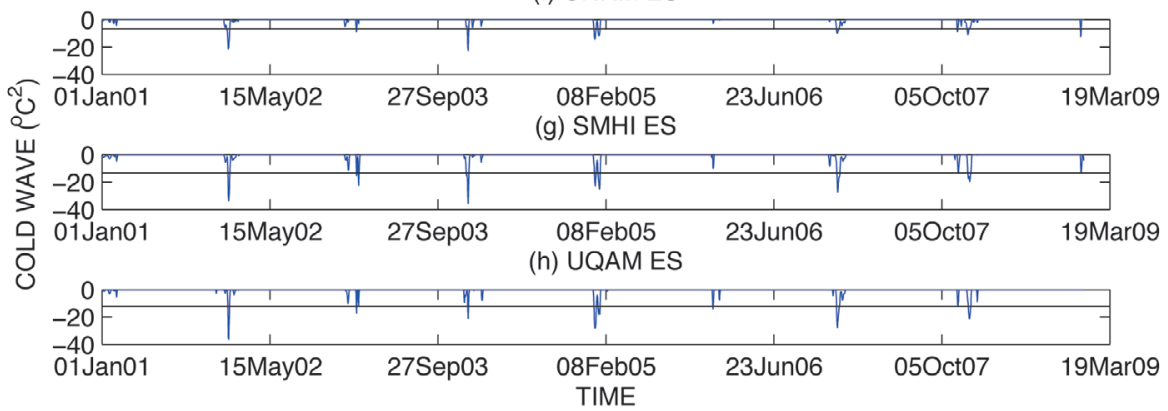

Figure 4. Same as Fig. 3 but for Eastern Sahel (ES). 
(a) ERAINT LS
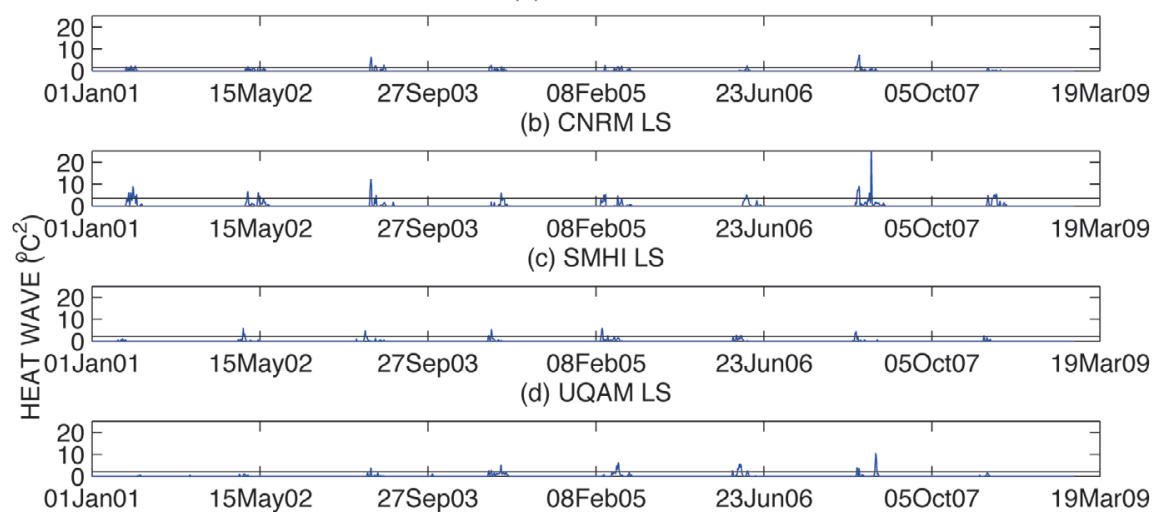

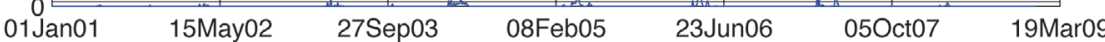

(e) ERAINT LS
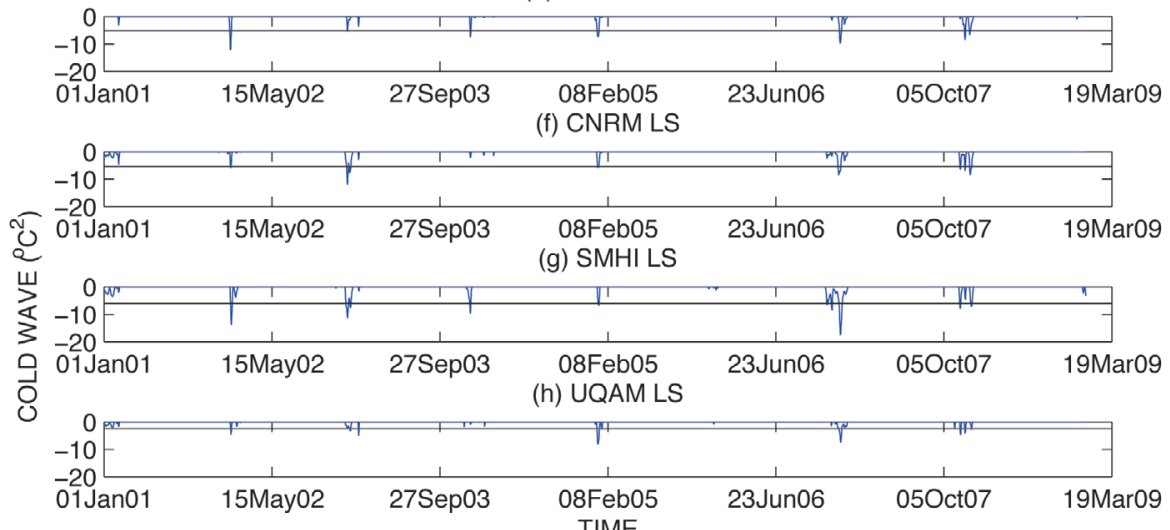

Figure 5. Same as Fig. 3 but for Lower Sahel (LS).

(a) ERAINT GS
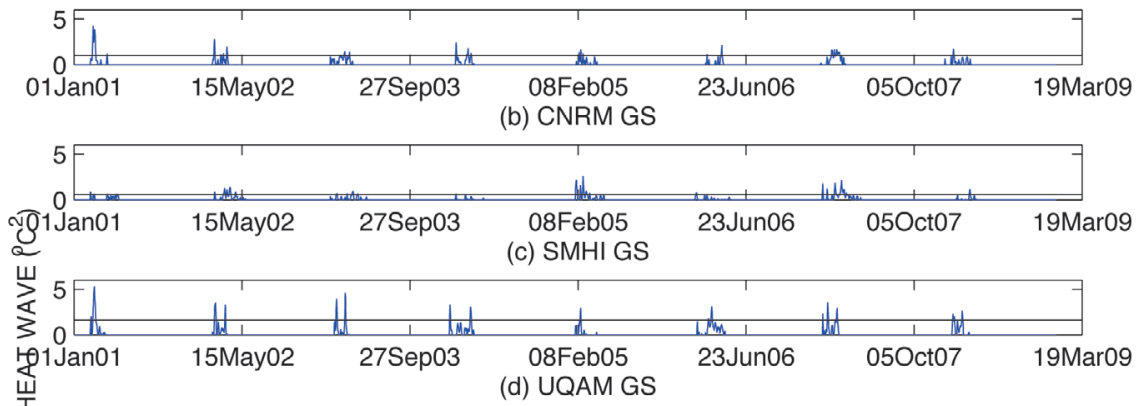

ய

(d) UQAM GS

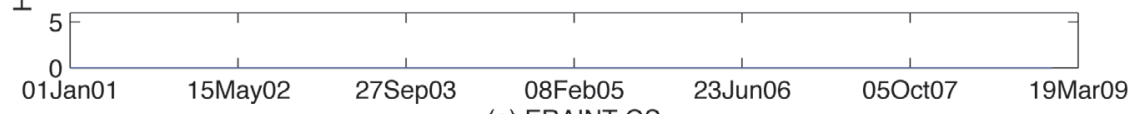

(e) ERAINT GS

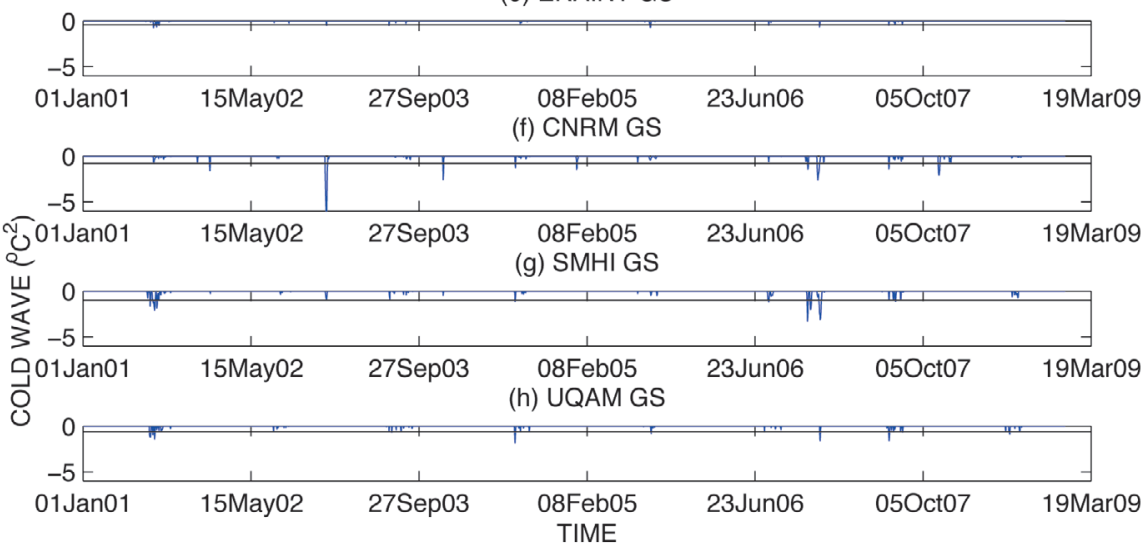

Figure 6. Same as Fig. 3 but for Guinea-Savannah (GS). 


\begin{tabular}{lcccccccc}
\hline & \multicolumn{2}{c}{ Western Sahel } & \multicolumn{2}{c}{ Eastern Sahel } & \multicolumn{2}{c}{ Lower Sahel } & \multicolumn{2}{c}{ Guinea - Savannah } \\
\hline & $95^{\text {th }}$ & $5^{\text {th }}$ & $95^{\text {th }}$ & $5^{\text {th }}$ & $95^{\text {th }}$ & $5^{\text {th }}$ & $95^{\text {th }}$ & $5^{\text {th }}$ \\
CNRM & 309.00 & 290.05 & 305.28 & 288.33 & 303.78 & 296.50 & 300.30 & 296.70 \\
SMHI & 307.80 & 289.90 & 304.70 & 287.73 & 304.90 & 297.50 & 301.90 & 296.50 \\
UQAM & 307.10 & 288.73 & 305.50 & 289.20 & 303.20 & 297.03 & 302.68 & 295.83 \\
ERAINT & 309.39 & 291.61 & 306.88 & 290.36 & 306.55 & 297.91 & 302.50 & 297.25 \\
\hline
\end{tabular}

Table 2. $95^{\text {th }}$ and $5^{\text {th }}$ percentiles of mean daily temperature for the reference period of 1989-2000.

over the Lower Sahel. The mode is the only one that controls temperature variations in the Western and Eastern Sahel; it also contributes a major part of the temperature variations in the lower Sahel region. PC3 contributes the second highest variation in temperature over the Lower Sahel. Temperature variation at the Guinea-Savanna is mainly controlled by PC1. The contributions of the different modes of variation are obvious in Figure 1. The area averaged temperatures on the days with highest negative scores for PC2, PC3 and $\mathrm{PC} 1$ are also the lowest relative to other PCs for the corresponding temperature regions.

Ward's method which has the best performance in the hierarchical clustering, having cluster members which are more distinct to the members of other clusters is used for the final clustering. A minimum of 161 stations with maximum spacing can be over West Africa based on $300 \times 300 \mathrm{~km}^{2}$ coordinates. Using this value in equation (1) results in eight number of clusters. The Clarks and Hosking [1986] and the natural breaks in cluster pattern obtained from Ward's method suggest eight clusters. Therefore, eight clusters are retained in the three sets of cluster analyses performed on the nine significant PCs retained in each of the analyses in the three periods.

\subsection{Excess Heat}

The high and low mean daily temperatures at $95^{\text {th }}$ and $5^{\text {th }}$ percentiles respectively calculated from the reference mean daily data (1989 to 2000) are shown in Table 2. Considering the Era Interim reanalysis data, 95th percentile temperature is highest at the Western Sahel (309.4 K) followed by the Eastern Sahel (306.9) and the minimum is at the Guinea-Savannah region. The highest value of 5 th percentile low temperature is at the lower Sahel $(297.9 \mathrm{~K})$ which is very close to the value at the Guinea-Savannah. The gap between the $95^{\text {th }}$ and $5^{\text {th }}$ percentile temperature values at the regions is least at the Guinea-Savannah and increases latitudinally towards the Western Sahel. The CNRM-ARPEGE simulates $95^{\text {th }}$ and $5^{\text {th }}$ percentile temperatures very close to the Era Interim reanalysis data at the Western Sahel (Table 2) but with negative bias. The good performance of ARPEGE in simulating mean monthly temperature over the entire Sahel is documented by Gbobaniyi et al. [2013]. Though this corroborates our findings at the Western Sahel, their results are not directly comparable to the findings of this study for some reasons; first, the temperature regions are not the same, second, the temporal scales are not the same, this study is based on daily temperature, theirs is on monthly temperature and third, they worked on mean temperature whearas this study is on lower and upper tails of daily temperature. UQAM performs better at the Eastern Sahel while SHMI shows the best skill at the lower Sahel. UQAM simulates the $95^{\text {th }}$ percentile better than all other models at the Guinea - Savannah while CNRM-ARPEGE is best at 5 th percentile over the area. These three RCMs are skilful in simulating the $95^{\text {th }}$ and $5^{\text {th }}$ percentiles of temperatures but the areas of their skills differ. Temperature is relatively stable at the Guinea-Savannah but varies more at the Sahel. So, the range of daily temperature is lowest at the Guinea-Savannah (Table 2) and magnitude of heat or cold wave is expected to be the lowest here.

The generalized Pareto distribution based on Pareto Principle [Juran, 1974; Paul et al., 1997] gives a turning point of $80^{\text {th }}$ percentile of the distribution function. This coincides with the obtained empirical turning point for the cumulative frequency distribution with a value very close to $80^{\text {th }}$ percentile. Therefore the Pareto principle is applied for both the severe heat and cold wave thresholds. The severe cold wave threshold is $20^{\text {th }}$ percentile. The threshold values for severe heat and cold waves for the different datasets and regions are shown as a black horizontal line in Figures 3 to 6 .

4.3 Results from the Reanalysis Data for severe heat and Cold waves

At the WS heat wave occurs intermittently but lingered for up to 30 days from 04 June to 03 August in 2001. However severe heat wave occurs for only six 
days during the period. There is a general increase in the amplitude of heat wave on annual basis from 2001 to 2008. The frequency of extreme heat wave remains more or less the same over the years (Figure 3). Severe heat wave occurs mostly in the month of June and July but sometimes varies at the beginning and ending of August. In 2002, it only occurred once in September. From the analysis, 2002 recorded the highest number of days with severe heat wave event; most of which fall within the month of July. Severe cold wave occurs in this temperature region from 2005 to 2008 between December and February but with a low magnitude and in only a few days.

Magnitude of heat wave is highest at ES. Severe heat wave at ES is experienced in May, June, July and August but mostly in May and June. Highest frequency of severe heat wave occurs in 2007 (May - 14 days and June - 5 days) and 2008 (May - 11 days and June - 8 days). Year 2007 is globally termed the second warmest year in the century with temperature tallying with1998 value [NASA, 2008]. This reveals global warming signature on the frequency of heat wave occurrence at ES. There is a general increase in the amplitude of heat wave over the years (Figure 4), this can be linked to global warming. The temperature of West Africa is positively correlated to tropical oceanic oscillations (Figure 8), so when the indices of the tropical oceanic circulation are high and positive there is tendency for heat wave to intensify over West Africa. Severe cold wave occurs almost every year between December and February with higher magnitude in this region compared to WS and other regions.

At LS, severe heat wave event frequently occurs in March, April and May. Year 2003 records the highest frequency of extreme heat wave event mostly in April. Years 2003 and 2007 are characterised with high amplitude of heat wave, other years have generally low amplitude (Figure 5). Cold wave generally has lower magnitude and number of days with severe events, compared to ES. It occurs from 2002-2007 between December and February in this temperature region.

At the Guinea-Savannah, extreme heat wave mostly occurs in February and March [Abiodun et al., 2013] but sometimes in early April [2006]. Abiodun et al. [2013] also found greatest warming in Sudan-Savannah ecological zone in March. Severe heat wave event has highest frequency of occurrence in 2007 (Figure 6). This lingers almost throughout March, having a sum of 20 days. In this region, there is little severe cold wave occurrence, the few cold wave occurrences have very low magnitude compared to all other regions.

Generally, heat wave occurrence migrates from February/March at GS through the LS and ES to WS between June and August. This is similar to the ITCZ movement [Adeniyi and Nymphas, 2013; Adeniyi, 2014a and b). This finding corroborates the previous findings that seasonal evolution of the surface temperature is dominated by the hot Sahara Thermal Low (STL) and that there is a link between the STL and ITCZ over West Africa [Thorncroft et al., 2011; Fontaine et al., 2013; Adeniyi, 2014a]. Lavaysse et al. [2009] observed that the seasonal fluctuations of the ITCZ synchronize with the seasonal movement of the STL. The cross-equatorial movement of thermal equator between the Tropic of Cancer at the northern hemisphere and the Tropic of Capricorn at the

(a) ES COLD WAVE

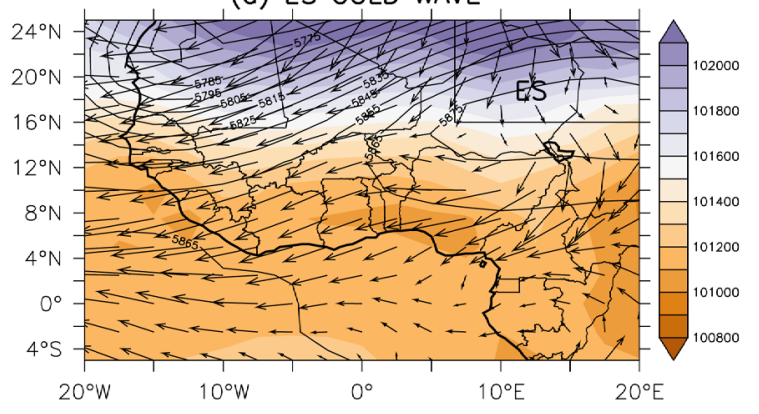

(b) ES HEAT WAVE

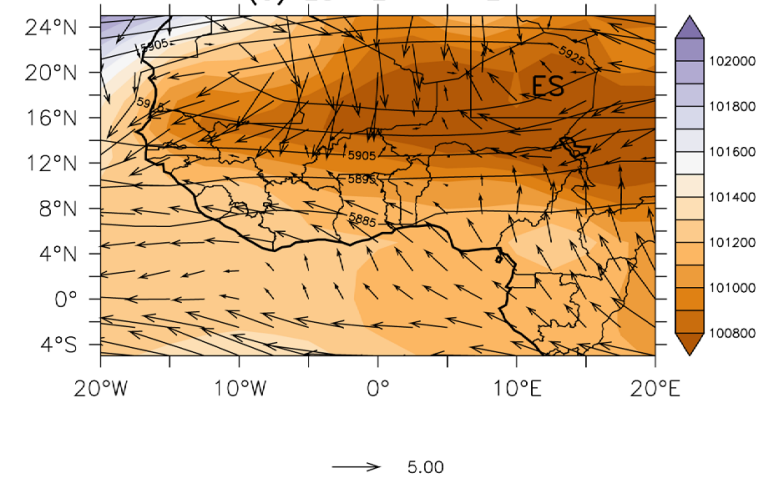

Figure 7. Five day composites of sea level pressure $(\mathrm{Pa})$ in shade, $500 \mathrm{hPa}$ geopotential height $(\mathrm{m})$ as contour and $850 \mathrm{hPa}$ wind (ms1) as vectors overlay at the Eastern Sahel (ES) for (a) cold wave and (b) heat wave occurrences. The five days used for cold wave are 23 to 27 December 2003 while those used for heat wave are 27 to 31 May 2007. The contour interval is $10 \mathrm{~m}$.

southern hemisphere explains the timing of heat wave occurrence at the different regions of West Africa. The thermal equator is the band of highest temperature around the globe which moves to and fro the two tropics with the sun [Vasquez, 2009]. Its movement is accompanied by a low pressure region where the trade winds from the north and the south meet. This is nothing but the ITCZ and the region of ITCZ 
(a) PDO

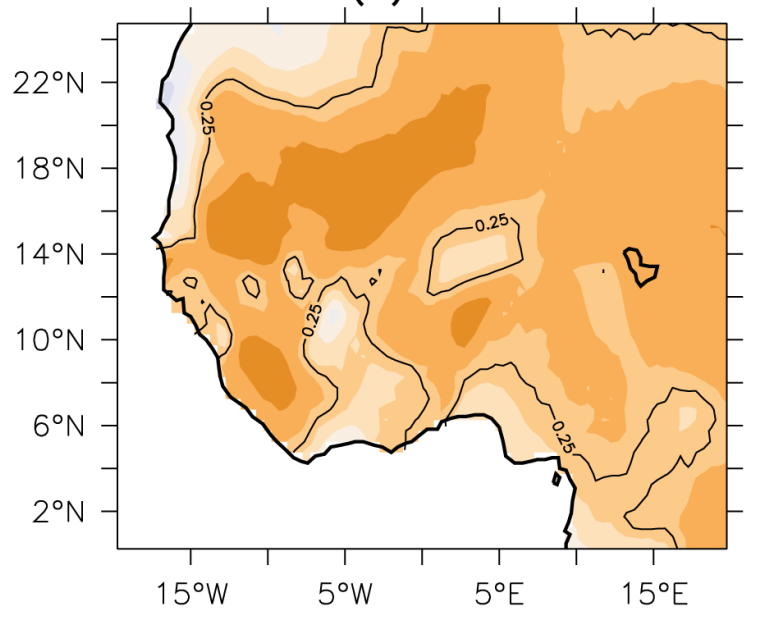

(c) TNA

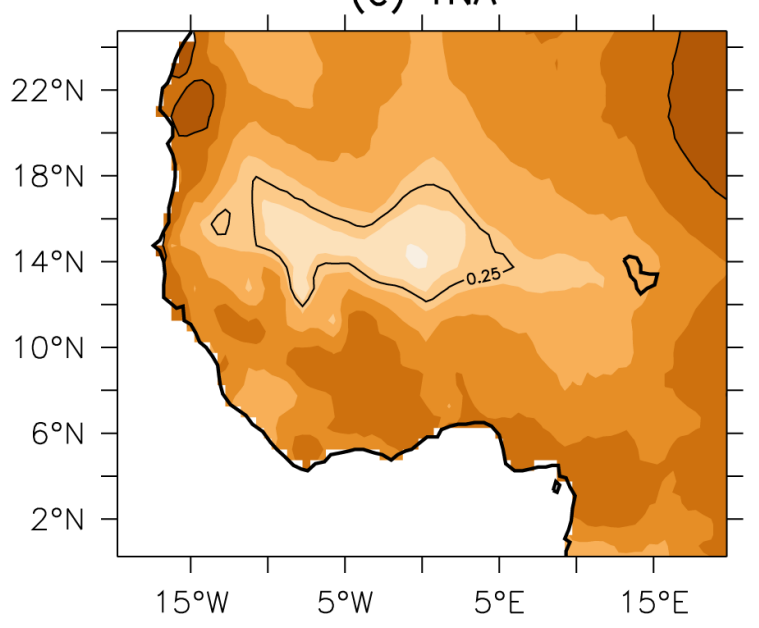

(b) AMO

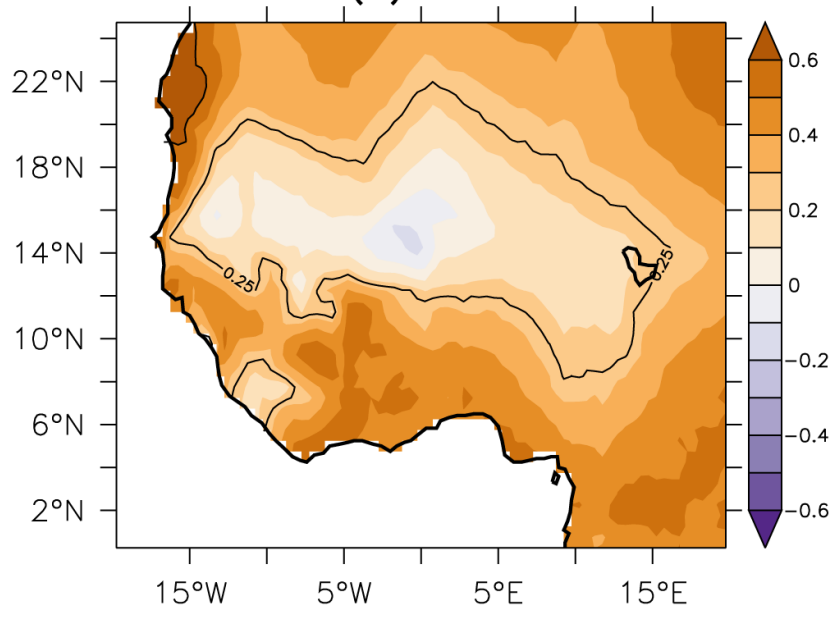

(d) DMI

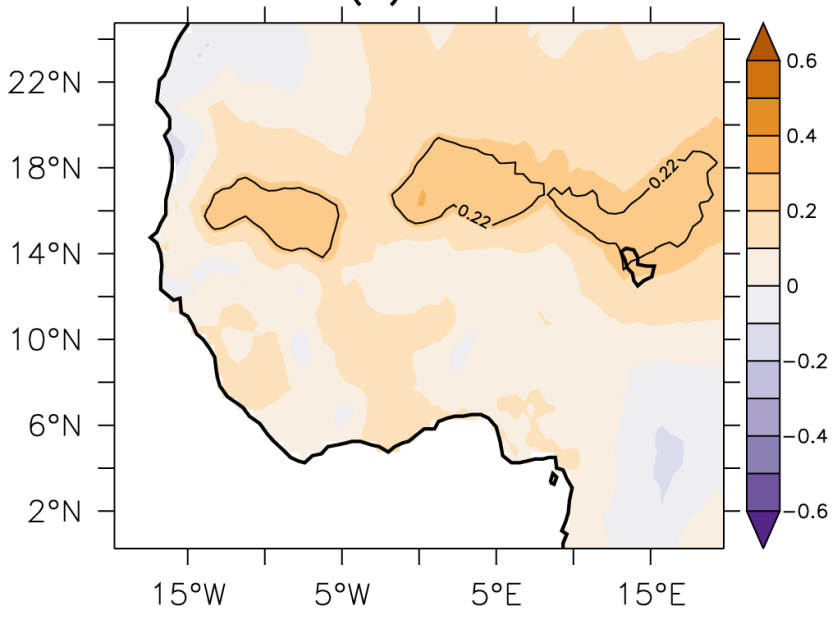

Figure 8. Coefficient of correlation between temperature and (a) Pacific decadal oscillation, (b) Atlantic multidecadal oscillation, (c) Tropical north Atlantic and (d) Dipole mode of Indian Ocean over West Africa during JJA. Significant correlations at 0.05 level are shown in contour in a-c while significant correlation at 0.1 level are shown in contour in d. Pacific decadal oscillation is AMJ while the Dipole mode of Indian ocean is MJJ.

will normally influence the region of the thermal low since that is the region of highest temperature which usually habours thunderstorm activity [Schneider et al., 2014]. The thermal equator moves with the sun and it determines seasons all over the globe [Vasquez, 2009]. The closer a region to the thermal equator at a particular time determines its temperature and the possibility of heat or cold wave occurrence. The thermal equator gets to the Eastern Sahel in June, that is why heat waves usually occur mostly in May and June at ES. The thermal equator gets to the equator in March when it is moving to the tropic of Cancer and it also passes through the equator in September while returning to the Tropic of Capricorn. It gets to the Tropics of Capricorn in December, at this time; the Sahel is having its highest distance from the thermal equator, so this partly explains why cold waves prevail in December at the Sahel.

\subsection{Dynamics of heat and cold waves}

High correlation between geopotential height at $500 \mathrm{hPa}$ and temperature over the tropics is well documented [Hafez and Almazroui, 2015; Knapp and Yin, 1996]. Buoyancy and rising of warm air parcel and sinking of cold one allow geopotential height to be high at the region of high temperature. Based on this fact, the region affected by heat wave is expected to have higher $500 \mathrm{hPa}$ geopotential height than the other regions. Also the region affected by cold wave should be characterised by lower $500 \mathrm{hPa}$ geopotential height on such days. Composite of geopotential height and wind vector are examined for five days with severe heat wave and cold wave over the Eastern Sahel. The sea level pressure clearly shows low surface pressure center at ES during the heat wave period; while it shows high surface pressure center at ES during the cold wave period. The $500 \mathrm{hPa}$ geopotental 
height on the other hand shows high mid tropospheric pressure center at the ES during heat wave period and low mid tropospheric pressure center during cold wave. Persistence of simultaneous warm core low pressure center at the surface and warm core high at the middle troposphere over a particular area increases the frequency of heat waves. On the other hand, when the simultaneous occurrence of cold high pressure center at the surface and cold low pressure center at the middle troposphere persists in an area; the number of days with heat wave increases. The magnitude of the pressure gradient controls the amplitude of the waves. The (surface) $850 \mathrm{hPa}$ wind vectors reveal the source of wind that results in either a cold or a heat wave event (Figure 7). Northerly and north-easterly winds prevail during cold wave events while southerly and southeasterly wind increase. The highest magnitude and frequency of cold wave occurrence at the ES can be due to the prevailing cold northerly airmass over the area during cold wave events. The location of mountains within and around the region can also strengthen cold wave event in the area by entrapping the cold air that reaches the region.

4.5 Result of influence of oscillation of tropical oceans on temperature

Figure 8 shows the correlation coefficient between temperature and tropical oceanic circulation indices during June-August season. Significant correlations at 0.05 level are shown in contour in Figure 8a-c. Due to the weak link observed between DMI and temperature over West Africa, the level of significance is relaxed to 0.1 , so significant correlation at 0.1 level are shown in contour in Figure 8d. The PDO, AMO and TNA all have strong positive link with temperature over West Africa. The area where there is weak correlation between PDO and temperature is influenced strongly by AMO and vice versa (Figure 8a,b). The TNA (Figure 8c) also has a very strong link with temperature over West Africa similar to AMO (Figure $8 \mathrm{~b}, \mathrm{c}$ ). This is not surprising since the two indices are for the Atlantic Ocean, only that the latter has decadal variation. The TNA has a wider spatial coverage of positive pattern of correlation over West Africa than AMO and influences strongly, the areas of weak correlation in AMO at the Guinea Savannah.

Though the DMI is not strongly correlated to temperature over West Africa, it has significant correlation with temperature at the areas of weaker correlation in TNA and AMO (Figure 8b,c,d). The four tropical oceanic indices complement themselves in influencing the temperature of West Africa. Variations in heat and cold waves frequency and amplitude can be linked to variations in the tropical oceanic oscillations. Any year with high magnitude of these indices will likely experience increased frequency and magnitude of heat wave or cold wave depending on the phases of the tropical indices.

\subsection{Validation of simulated heat and cold waves}

Another objective of this investigation is to validate the heat and cold wave simulation from three CORDEX models (CNRM-ARPEGE, SMHI and UQAM). The simulated heat and cold waves are compared with the heat and cold wave obtained from reanalysis data in order to examine the performance of the regional climate models over the study area.

At the WS, the reanalysis data shows June and July as heat wave period over the years [2001 - 2008). These two months are also observed in the models but CNRM-ARPEGE and SHMI also includes August and September (Figure 3). SMHI simulates higher magnitude of heat wave with respect to Era Interim reanalysis. The ES includes May in the heat wave period at WS. The model with closest distribution of simulated heat wave with the reanalysis data is UQAM (Figure 4). This zone exhibits the highest magnitude of cold wave. For LS, the reanalysis data show high frequency of heat wave in March, April and May. Only SHMI has a different result (January and February). QUAM and CNRM-ARPEGE simulate heat wave comparable with the result from the reanalysis data (Figure 5). Almost all the regional climate models are in agreement with the reanalysis data at GS except QUAM which has no record of heat wave event (Figure 6). This shows that daily temperatures are lower than what they were during the climatological period over GS in UQAM simulation. This is strange because UQAM simulates 95th percentile of the reference period closest to and higher than Era Interim 95th percentile. Months with high frequency of heat wave are February, March and April.

Cold wave and its extreme occurrence are frequent in reanalysis data and the regional models during January and December for all the years (20012008) and for all the zones except GS. GS has cold wave and its severity during July and August in the reanalysis data and models. The simulations in GS are different either with lower frequency or higher depending on the year. No cold wave is simulated in some years. UQAM simulates the closest pattern of heat wave to the reanalysis heat wave at the Guinea-Savannah. Relative to Era Interim reanalysis, the models have good skill in simulating cold wave except at GS (Figures 3-6). 


\section{Conclusion}

Owing to the negative impact of heat and cold waves on the society and economy of a region, this paper documents the state of heat and cold waves over the homogeneous temperature regions of West Africa. Also, the performances of CORDEX models in simulating the observed heat and cold waves are presented. Global warming and tropical oceanic oscillations are influencing the amplitude and frequency of heat waves over West Africa. Heat wave amplitude has increased from 2001-2008, while the frequency increased in 2007 over West Africa. This same year 2007 is the second warmest year in the century [NASA, 2008]. The consequences of continuity of such influence may be disastrous for a developing region like West Africa. Little or no occurrence of cold waves over GS in Decembers shows the great reduction in harmattan occurrence over the temperature region. This cannot be unconnected with the warming effect of the Atlantic Ocean on the temperature region. Temporal and northward movement of heat waves with the thermal equator from GS region in February-March to the WS between June and August is linked to the movement of the thermal equator and thermal low between the Tropic of Cancer and Tropic of Capricorn. The CNRM-ARPEGE model is capable of simulating the period and frequency of heat wave at WS, ES and LS but with higher amplitude of severe heat wave. The model also has a fair performance at the LS except for simulating higher frequency than observed. The SMHI model simulates heat wave at earlier period than ERAINT with generally higher amplitude. It gives higher frequency of heat wave at LS. The UQAM simulates comparable heat wave amplitude and frequency at WS, and ES but does not detect heat wave at GS. All the models have good performance in simulating cold wave except at GS. CNRM- ARPEGE is recommended for projection of heat and cold waves over West Africa. However, allowance should be made for the high frequency simulation syndrome associated with the model. UQAM can be used for heat and cold wave projection at the WS and ES. Information on projected heat and cold waves are needed over West Africa for possible adaptation and mitigation plans.

\section{Data and Sharing Resources}

The regional climate model output used in this study can be downloaded from https: / / esgf-index1.ceda.ac.uk/ search/ cordex-ceda.

The reanalysis temperature data used in this study can be downloaded from apps.ecmwf.int/ datasets / data / interim-full-daily.

The geopotential height, sea level pressure and wind data are available at http: / / w ww.esrl.noaa.gov/psd/data/gridded/ data.ncep.reanalysis.html.

Acknowledgements. The authors are grateful to the institutions that participated in CORDEX experiment for making the model simulation outputs available for this work. We appreciate the reanalysis data provision by the European Center for Medium-Range Weather Forecasts (ECMWF). We also thank the national oceanic and atmospheric administration for making the NCEP reanalysis sea level pressure, geopotential height and wind data available for this study.

\section{References}

Abatan, A. A., Abiodun, B. J., Kamoru, A., Lawal, K. A. and W. J. Gutowski Jr (2015). Trends in extreme temperature over Nigeria from percentile-based threshold indices. Int. J. Climatol., DOI: 10.1002/ joc. 4510 .

Abdussalam, A. F. (2015). Changes in indices of daily temperature and precipitation extremes in northwest Nigeria. Science World Journal, 10 (2). Available at: www.scienceworldjournal.org ISSN 1597-6343.

Abiodun, B. J., Lawal, K. A., Salami, A. T., A. A. Aba$\tan$ (2013). Potential influences of global warming on future climate and extreme events in Nigeria. Reg. Environ. Change, 13, 477 - 491 DOI: 10.1007 / s10113-012-0381-7.

Adeniyi, M. O. (2009). Determination of heat stress in the tropical urban area of Ibadan, Southwestern Nigeria. International Journal of Natural and Applied Sciences, 5(3), 235-243.

Adeniyi, M. O. (2014a). Sensitivity of different convection schemes in RegCM4.0 for simulation of precipitation during the Septembers of 1989 and 1998 over West Africa. Theoretical and Applied Climatology, 115(1-2), 305-322, DOI 10.1007/ s00704-013-0881-5.

Adeniyi, M. O. and E. F. Nymphas (2013). Estimation of surface energy fluxes from bare ground in a tropical station using Priestley Taylor method. Journal of Science and Technology, 23(1), 41-54.

Alexander, L. V., Zhang, X., Peterson, T. C., Caesar, J., Gleason, B., Klein Tank, A. M. G., Haylock, M., Collins, D., Trewin, B., Rahimzadel, F., Tagipour, A., Rupa Kumar, K, Revadekar, J., Griffiths, G., Vincent, L., Stephenson, D. B., Burn, J., Aguilar, E., Brunet, M., Taylor, M., New, M., Zhai, P., Rusticucci, M. and J. L.Vazquez-Aguirre (2006). Global observed changes in daily climate extremes of 
temperature and precipitation. J. Geophys. Res., 111, D05109. DOI: 10.1029/2005JD006290.

Awan, J. A. Baea, D. and K. Kimb (2015). Identification and trend analysis of homogeneous rainfall zones over the East Asia monsoon region. Int. J. Climatol. 35, 1422 - 1433. DOI: 10.1002 /joc. 4066 .

Cattell, R.B. (1966). The scree test for the number of factors. Multivar. Behav. Res. 1, 245 - 276. doi:10.1207/s15327906mbr0102_10.

Changnon, S. A., Kunkel, K. E. and B. C. Reinke (1996). Impacts and responses to the 1995 heat wave: a call to action. Bull. Am. Meteorol. Soc., 77, 1497 - 1506.

Clark W. A. V., and P.L. Hosking (1986). Statistical methods for geographers. Wiley 518, pp ISBN 0471818070

Comrey, A.L, and H.B. Lee (1992). A first course in factor analysis. Hillsdale, NJ: Erlbaum.

Donat. M. G., Peterson, T. C., Brunet, M., King, A. D., Almazroui, M., Kolli, R. K., Boucherf, D., Al-Mulla, A. Y., Nour, A. Y., Aly, A. A., Nada T. A.A, Semawi, M. M., Al Dashti, H. A., Salhab, T. G., El Fadli, K. I, Muftah, M. K., Eida, S. D., Badi, W., Driouech, F., Khalid, E. 1. Rhaz, K., Abubaker, M. J. Y., Ghulam, A. S., Erayah, A.S., Mansour, M. B., Alabdouli, W. O., Al Dhanhani, J. S. and M. N. Al Shekaili (2013). Changes in extreme temperature and precipitation in the Arab region: long-term trends and variability related to ENSO and NAO. Int. J. Climatol., DOI: 10.1002 /joc.3707.

Easterling, D. R. et al. (1997). Maximum and minimum temperature trends for the globe. Science, 277, $364-367$.

Eludoyin, O. M., Adelekan, I. O., Webster, R. and A. O. Eludoyin (2014). Air temperature, relative humidity, climate regionalization and thermal comfort of Nigeria. Int. J. Climatol., 34, 2000 - 2018. DOI: $10.1002 /$ joc. 3817 .

Enfield, D.B., Mestas, A.M., Mayer, D.A. and L. Cid-Serrano (1999). How ubiquitous is the dipole relationship in tropical Atlantic sea surface temperatures? J.G.R.-O, 104, 7841-7848.

Enfield, D.B., Mestas-Nunez, A. M. and P.J. Trimble (2001). The Atlantic multidecadal oscillation and it's relation to rainfall and river flows in the continental U.S. Geophysical Research Letters, 28, 20772080.

Frich, P., Alexander, L.V., Della-Marta, P., Gleason, B., Haylock, M., Tank, A. M. G. K. and T. Peterson (2002). Observed coherent changes in climatic extremes during the second half of the twentieth century. Clim. Res., 19, 193 - 212.

Fontaine, B., Janicot, S. and P.-A. Monerie (2013). Recent changes in air temperature, heat waves occurrences, and atmospheric circulation in Northern Africa. J. Geophys. Res. Atmos., 118, 8536 - 8552. DOI: $10.1002 /$ jgrd.50667.

Gbobaniyi Emiola Gbobaniyi,a,b Abdoulaye Sarr, Mouhamadou Bamba Sylla,d Ismaila Diallo,e Chris Lennard,f Alessandro Dosio,g Arona Dhi'ediou,h Andre Kamga,i Nana Ama Browne Klutse,j Brue Hewitson,f Grigory Nikulina and Benjamin Lampteyk (2013) Climatology, annual cycle and interannual variability of precipitation and temperature in CORDEX simulations over West Africa. INTERNATIONAL JOURNAL OF CLIMATOLOGY Int. J. Climatol. (2013) Published online in Wiley Online Library (wileyonlinelibrary.com) DOI: 10.1002 / joc. 3834

Gbode, I. E., Akisanola, A. A. and V. O. Ajayi (2015). Recent changes of some observed climate extreme events in Kano. International Journal of Atmospheric Sceinces, ID, 298046. DOI: http://dx.doi. org / 10.1155/2015/298046.

Gong, X. and M. B. Richman (1995). On the application of cluster analysis to growing season precipitation data in north America east of the Rockies. J. Climatol. 8, 897 - 931.

Guirguis, K., Gershunov, A., Tardy, A. and R. Basu (2014). The Impact of Recent Heat Waves on Human Health in California. J. Appl. Meteor. Climatol., 53, 3 - 19. DOI: http://dx.doi.org/10.1175/ JAMC-D-13-0130.1.

Hafez, Y. Y. and M. Almazroui (2015). A recent study on the relationship between global radiative forcing and global annual climatic variability. Atmospheric and Climate Sciences, 5, 23-55.

Harris, I., Jones, P.D., Osborn, T.J. and D.H. Lister (2014), Updated high-resolution grids of monthly climatic observations in the CRU TS3.10 Dataset. Int. J. Climatol., 34,623-642. DOI: 10.1002/ joc. 3711 .

Juran, J. M. (1974). Quality Control Handbook. Mc Graw Hill Higher Education 3rd Edition pp. 1600.

Kaiser, H.F. (1960). The application of electronic computers to factor analysis. Educ. Psychol. Meas. 20, 141 - 151. doi:10.1177/0013164 46002000116.

Kalkstein, L. S. and K. M. Valimont (1986). An evaluation of summer discomfort in the United States using a relative climatological index. Bull. Amer. Meteor. Soc., 67, 842 - 848.

Knapp, P. A. and Z. - Y. Yin (1996). Relationships 
between geopotential heights and warming and cooling periods temperature in the south-eastern US during wintertime. Int. J. Clim., 16,195-211.

Kunkel, K. E., Pielke, Jr R. A. and S. A. Changnon (1999). Temporal fluctuations in weather and climates extremes that cause economic and human health impacts: A review. Bulletin of the American Meteorology Society, 80(6), 1077-1098.

Lavaysse, C., Flamant, C., Janicot, S., Parker, D. J., Lafore, J. P., Sultan, B. and J. Pelon (2009). Seasonal evolution of the West African Heat Low: a climatological perspective. Clim. Dyn., 33, 312 - 330.

Leeuwen J. V. (1998), ed. Handbook of Theoretical Computer Science Amsterdam: Elsevier: Vol.A, Algorithms and complexity. ISBN 0262720140. OCLC 247934368.

Mantua, N.J., Hare, S.R., Zhang, Y., Wallace, J.M. and R.C. Francis (1997). A Pacific interdecadal climate oscillation with impacts on salmon production. Bulletin of the American Meteorological Society, 78, pp. 1069-1079.

Meehl, G. A. and C. Tebaldi (2004). More intense more frequent, and longer lasting heatwaves in the 21st century. Science, 305, 994-997.

Moberg, A., Jones, P. D., Barriendos, M., BergstoÈm, H., Camuffo, D., Cocheo, C., Davies, T. D., DemareÂe, G., Maugeri, M., Martin-Vide, J., Rodriguez, R. and T. Verhoeve (2000). Dayto-day temperature variability trends in 160-to-275-year long European instrumental records. J. Geoph. Res. Atmos., 105(D18) 22849-22868.

Mouhamed, L., Traore, S. B., Alhassane, A. and B. Sarr (2013). Evolution of some observed climate extremes in the West African Sahel. Weather and Climate Extremes, 1, 19 - 25.

Nairn, J. and R. Fawcett (2013). Defining heatwaves: heatwave defined as a heat-impact event servicing all community and business sectors in Australia. The Centre for Australian Weather and Climate Research- a partnership between CSIRO and the Bureau of Meteorology, CAWCR Technical Report No. 060.

NASA/Goddard Space Flight Center (2008). 2007 Was Tied As Earth's Second Warmest Year. ScienceDaily. ScienceDaily, 17 January 2008. <www.sciencedaily.com/releases / 2008/01/ 080116114150. htm $>$. Accessed 14 October 2016.

New, M., Hewitson. B., Stephenson, D.B., Tsiga, A., Kruger, A., Manhique, A., Gomez, B., Coelho, C. A. S., Masisi, D. N., Kululanga, E., Mbambalala, E., Adesina, F., Saleh, H., Kayanga, J., Adosi, J., Bula- ne, L., Fortunata, L., Mdoka, M. L. and R. Lajoie (2006). Evidence of trends in daily climate extremes over southern and West Africa. J. Geophys. Res., 111, D14102. DOI: 10.1029/2005JD006289.

Nicholson, S. E., Some, B. and B. Kone (2000). An analysis of recent rainfall conditions in West Africa, including the rainy seasons of the $1997 \mathrm{El} \mathrm{Niño}$ and the 1998 La Niña years. J. Clim., 13, 2628 - 2640.

Nikulin, G., Jones, C., Giorgi, F., Asrar, G., Buchner, M., Cerezo-mota, R., Christensen, O.B., DeQue, M., Fernandez, J., Hansler, A., Meijgaard, E.V., Samuelsson, P., Sylla, M.B. and L. Sushama (2012). Precipitation climatology in an ensemble of CORDEX-Africa regional climate simulations. J. Climate, 25, 6057 - 6078 .

Oguntunde, P. G., Abiodun, B. J. and G. Lischeid (2012). Spatial and temporal temperature trends in Nigeria, 1901 - 2000. Meteorol. Atmos. Phys., 118, 95 - 105. DOI: 10.1007 / s00703-012-0199-3.

Parmesan, C., Root, T. L. and M. R. Willig (2000). Impacts of extreme weather and climate on terrestrial biota. Bulletin of the American Meteorological Society, 81, 443 - 450.

Paul E., Claudia K., M. Thomas (1997). Modelling extremal events for insurance and finance. p. 162. ISBN 9783540609315.

Peterson, T. C., Taylor, M. A., Demeritte, R., Duncombe, D. L., Burton, S., Thompson, F. and B. Gleason (2002). Recent changes in climate extremes in the Caribbean region. J. Geophy. Res.-Atmos., 107(D21). DOI: 10.1029/2002jd002251.

Rebetez, M. and M. Reinhard (2008). Monthly air temperature trends in Switzerland $1901-2000$ and 1975 - 2004. Theor. Appl. Climatol., 91, 27 - 34.

Robinson, P. J. (2001). On the Definition of a Heat Wave. J. Appl. Meteor., 40, 762-775.

Saji, N. H., B. N. Goswami, P. N. Vinayachandran, and T. Yamagata (1999). A dipole mode in the tropical Indian Ocean, Nature, 401, 360 - 363.

Tabachnick, B. G. and L. S. Fidell (2001). Using multivariate statistics (4th ed). Boston: Allyn and Bacon.

Schneider, T., Bischoff, T., and G.H. Haug (2014). Migrations and dynamics of the intertropical convergence zone. Nature, 513, 45-53. DOI:10.1038/ nature 13636.

Thorncroft, C. D., Nguyen, H., Zhang, C., and P. Peyrillé (2011). Annual cycle of the West African monsoon: regional circulations and associated water vapour transport. Q. J. R. Meteorol. Soc., 137, $129-147$.

Vasquez, T. (2009). The intertropical convergenze 
zone. Weatherwise Magazine,November/December, 2009. Available at: http://www.weatherwise. org / Archives / Back\%20Issues / 2009/ Nov-Dec\%20 2009/full-Intertropical-Converge.html. Consulted 16 November, 2016.

Ward, J.H. (1963). Hierarchical grouping to optimize an objective function. J. Am. Stat. Assoc. 58(301), $236-244$.

Watt, J. D. and L. Kalkstein (2004). The Development of a Warm-Weather Relative Stress Index for

Environmental Applications. J. Appl. Meteorol., 43, 503-513.

Zhang, Y., Wallace, J.M. and D.S. Battisti (1997). ENSO-like interdecadal variability: 1900-93. J. Climate, 10, 1004-1020.

${ }^{\star}$ Corresponding author: Mojisola Oluwayemisi Adeniyi,

Department of Physics, University of Ibadan, Ibadan, Nigeria e-mail: mojisolaadeniyi@yahoo.com

by Istituto Nazionale di Geofisica e Vulcanologia.

All rights reserved 